\title{
THE EFFECT OF SOME PATHOLOGICAL CONDITIONS UPON DYSPNEA DURING EXERCISE
}

\author{
I. Artificial Stenosis \\ By A. W. HEWLETT, J. K. LEWIS AND ANNA FRANKLIN \\ (From the Department of Medicine, Stanford Medical School) \\ (Received for publication, January 26, 1925) \\ INTRODUCTION
}

That dyspnea may occur during exercise and that it is more apt to occur under certain pathological conditions are commonplace observations; yet the physiological mechanisms involved are in part obscure. The effects of exercise have been studied mainly on normal individuals and relatively few observations have been made on patients or on normal persons who have been subjected to abnormal conditions. Pathological conditions may alter the response to exercise in various ways. Thus a given exercise may cause an excessive rise in the metabolic rate, or a given rise in the metabolic rate may be accompanied by an excessive stimulation of the respiratory center, whether through nervous influences, oxygen want, excess carbon dioxid, the formation of non-volatile acids or other factors. Furthermore pathological conditions may reduce the capacity of the external respiratory organs to meet the demands made upon them during exercise. From one or more of these causes, the individual finds it unusually difficult to cope with the respiratory strain imposed by the exercise. The resulting respiratory effort constitutes what we know as dyspnea.

Dyspnea may result when the passage of air through the larger air passages is obstructed, as occurs in stenosis of the larynx and trachea. The effect of such stenoses upon the respiration can be studied experimentally in man by having a normal subject breath through a tube that has been artificially narrowed to any desired extent.

Using such a method, Morawitz and Siebeck (1) found that the respirations altered immediately after the obstruction had been introduced and before there had been time for any change to occur in the composition of the alveolar air or of the blood. Unless the obstruc- 
tion was marked enough to cause a feeling of distress, no increase in the alveolar tension of carbon dioxid could be demonstrated, and in no case was the oxygen content of the blood altered. Immediately after introducing the obstruction, the respirations became slower and deeper, the midvolume of the lung became greater, and the dead space was increased. With milder degrees of stenosis, these changes disappeared immediately after the obstruction was removed. The prompt appearance and disappearance of these changes, together with the absence of demonstrable alterations in the composition of the alveolar air indicated that they were caused by changes in the nervous rather than the chemical control of respiration. If the stenosis was more marked and subjective feelings of distress were experienced, an increased carbon dioxid tension in the alveoli was found. Under such circumstances a chemical stimulation of the respiratory center contributed to the production of the altered respiration. Haldane (2), who also studied the effect of artificial stenosis upon the respiratory mechanism, found that the slowing of respiration preceded the increased depth of the individual respirations. He attributed the slowing to nervous influences. In accordance with the Hering-Breuer theory of nervous control, the respirations became slower, because, owing to the stenosis, it took longer for the lungs to reach a given position of in- or expiration. This slowing decreased the minute ventilation, carbon dioxid accumulated and stimulation of the respiratory center deepened the respirations. Thus according to Haldane the slow and deep respirations, characteristic of stenosis, depend in part upon nerve reflexes, in part upon carbon dioxid retention. Haldane found furthermore that very marked obstructions or moderate obstructions, when combined with muscular exercise, led to oxygen want and that when this occurred a more rapid and more shallow type of breathing appeared.

In the present study the effects of stenosis upon the volume of pulmonary ventilation during and after exercise were studied. Changes in the composition of the respired air were also investigated.

\section{METHOD OF STUDY}

In order to insure a uniform amount of exercise a treadmill was used, the steps being 7 inches high. On this treadmill a brake was so 
adjusted that the body weight of the subject sufficed to keep the steps moving at a rate of 80 per minute, as timed by a metronome. The subject (A. W. H.) breathed through a rubber mouth piece, the nose being closed with a clip. By means of flutter valves, the expired air was collected either in the recording spirometer described by Slonaker (3), or in a series of Douglas bags, the latter being used for gas analysis. Artificial stenosis was produced by introducing a bored cork into the rubber mouth piece. Two corks were used for this purpose. The larger bore, $8 \mathrm{~mm}$. in diameter and $27 \mathrm{~mm}$. long, caused only a slight sensation of obstruction during quiet breathing and moderate discomfort during the exercise. The smaller bore, $6 \mathrm{~mm}$. in diameter and $25 \mathrm{~mm}$. long, produced some discomfort during rest and progressive embarrassment during the exercise. With this degree of stenosis exercise could be continued only slightly beyond two minutes when air was breathed. Even the ascent of 100 steps, the standard used for recovery curves, caused marked respiratory distress.

Before the exercise a record of the respiratory volume or of the respiratory interchange of gases was obtained with the subject either sitting or standing. No effort was made to obtain basal figures for the position assumed either by a prolonged preliminary rest period or by omitting breakfast. The exercise consisted in ascending the treadmill at a uniform rate of 80 steps per minute. Recovery records were obtained with the subject sitting or standing, after having climbed 100 steps. In other experiments the respiratory changes were studied during the exercise itself. Particular attention was paid to the initial 100 steps and to the later period, when after three or four minutes of continued exercise, the conditions were approximately stationary.

The external work performed per minute consisted in lifting the body weight eighty 7 -inch steps. With a body weight of $157 \frac{1}{2}$ pounds, this would be equivalent to 1016 kilogrammeters of work per minute. The minute utilization of oxygen after four or more minutes of exercise approximated $2000 \mathrm{cc}$. If we subtract a resting oxygen consumption of 315 cc., there was left an excess consumption of 1685 cc. per minute which was equivalent to 8.194 calories, if a respiratory quotient of 0.85 be assumed. The heat equivalent of the external 
work performed was 2.380 calories and the net mechanical efficiency was 29.0 per cent. ${ }^{1}$

EFFECT OF STENOSIS UNDER RESTING CONDITIONS

The $8 \mathrm{~mm}$. bore, which produced hardly any sensation of obstruction during rest, did not definitely influence the respiratory rate, the minute volume or the composition of the expired air. The $6 \mathrm{~mm}$. bore invariably slowed the respiratory rate (table 1$)$. The average minute volume of air breathed was lessened in one series of experiments (table 5) but uninfluenced in the other (table 4).

TABLE 1

Effect of stenosis on respiratory rates

\begin{tabular}{|c|c|c|c|}
\hline & No obstruction & $8 \mathrm{~mm}$. bore & $6 \mathrm{~mm}$. bore \\
\hline . & per minute & per minute & per minute \\
\hline Resting. . . . . $\ldots \ldots \ldots \ldots \ldots$ & $16.5[10]$ & $17.1[8]$ & $13.6[6]$ \\
\hline First minute of exercise.......... & $27.6 \quad[9]$ & $21.0 \quad[4]$ & $16.7[5]$ \\
\hline Second minute of exercise. ... & 28.3 & $20.6[4]$ & $17.7[4]$ \\
\hline Continued exercise. . & 27.8 & 20.5 & \\
\hline
\end{tabular}

The unbracketed figures represent respiratory rates per minute. The bracketed figures give the number of observations averaged.

\section{EFFECT OF STENOSIS DURING EXERCISE}

Obstruction uniformly slowed the respiratory rates during exercise (table 1). Rates characteristic of the degree of obstruction appeared with the first few steps of exercise and remained practically constant thereafter. Changes in volume of respiration subsequent to the first few seconds of exercise were therefore due almost entirely to changes in the size of the individual respirations. The volume of respiration was invariably reduced by the $6 \mathrm{~mm}$. bore and to a lesser extent by the $8 \mathrm{~mm}$. bore. In all records the spirometer showed an abrupt increase in respiratory volume during the first ten seconds of exercise

${ }^{1}$ If the resting oxygen utilization were $270 \mathrm{cc}$. - a level reached by this subject in other experiments after a longer rest period-and if a respiratory quotient for the excess metabolism due to exercise were 1.00 , then the heat equivalent of the excess oxygen used would be 8.731 calories and the net mechanical efficiency 27.3 per cent. 
and a more gradual increase during the succeeding minute or two (table 2, fig. 1). Thereafter the volume of respired air remained approximately constant or increased very slowly. The rise in volume of ventilation observed at the onset occurred so promptly that it must be attributed in part to nervous influences, the gradual increase during the subsequent two minutes was due to an adjustment to the new metabolic conditions, while the final constant or nearly constant

TABLE 2

Effect of obstruction upon minute volume of pulmonary ventilation during exercise at 80 steps per minute

Volumes are expressed in liters and are not corrected for temperature or pressure.

\begin{tabular}{|c|c|c|c|}
\hline & No Obstruction & $\begin{array}{l}8 \mathrm{~mm} \text {. } \\
\text { Obstruction }\end{array}$ & $\begin{array}{l}6 \mathrm{~mm} \text {. } \\
\text { Obstruction }\end{array}$ \\
\hline Number of experiments averaged...................... & 7 & 3 & 3 \\
\hline 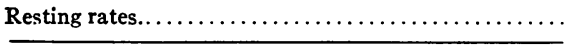 & 9.1 & 9.9 & 9.1 \\
\hline \multirow{5}{*}{$\cdot$} & 20.3 & 19.6 & 15.8 \\
\hline & 22.4 & 20.9 & 16.0 \\
\hline & 26.5 & 22.6 & 19.4 \\
\hline & 29.3 & 27.9 & 21.3 \\
\hline & 32.2 & 29.2 & 24.0 \\
\hline \multirow{6}{*}{$\begin{array}{l}\text { Minute volume in liters during e:sercise for } \\
\text { successive } 10 \text { second periods afte: the start. }\end{array}$} & 36.1 & 33.0 & 25.7 \\
\hline & 39.0 & 33.4 & 28.3 \\
\hline & 41.0 & 37.5 & 28.0 \\
\hline & 45.6 & 38.9 & 27.5 \\
\hline & 47.5 & 41.5 & 28.3 \\
\hline & 50.8 & 42.5 & 28.0 \\
\hline Minute volume after three minutes exercise... & 52.6 & 43.7 & \\
\hline Number of experiments averaged..... & 5 & 4 & \\
\hline
\end{tabular}

The exercise consisted of ascending steps at 80 steps per minute.

minute volume indicated either that a steady state had been established or that the maximum volume of ventilation had been reached. At each stage, the effect of obstruction in lessening the volume of respired air was evident. In the case of the $8 \mathrm{~mm}$. bore, the primary rise was only slightly less than without obstruction but the difference between the two gradually increased. The steady state eventually established showed a minute volume of approximately 44 liters, while without obstruction it was 53 liters. With the $6 \mathrm{~mm}$. bore, the pri- 
mary rise in minute volume was distinctly less, and with the second minute of exercise a maximum minute volume of less than 30 liters was attained. This was evidently insufficient for the establishment of a steady state, for increasing distress terminated the exercise at about the end of the second minute.

The effect of restricted pulmonary ventilation upon the respiratory

EFFECT OF STENOSIS UPON PULMONARY VENTILATION DURINO EXERCISE

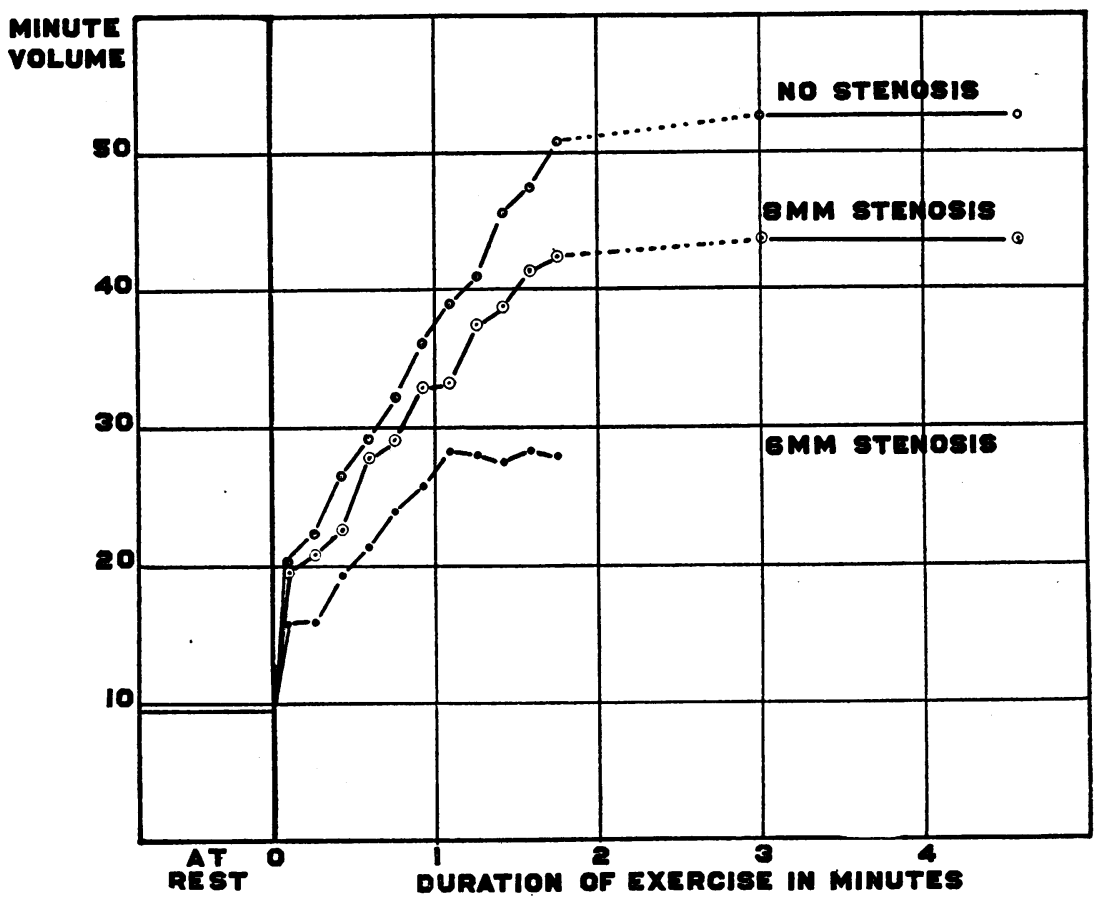

Fig. 1. Effect of Stenosis upon Minute Volume of Respiration during EXERCISE

Constructed from table 2

interchange of gases was studied during the first minute and a quarter of exercise (100 steps) and during the steady state attained after several minutes of continued exercise (table 4). During the first minute and a quarter of exercise, the lessened volume of ventilation caused by stenosis was accompanied by a corresponding relative reduction in the amount of carbon dioxid eliminated, this effect being much 
more pronounced with the marked obstruction. These obstructions therefore led to a retention of carbon dioxid in the body during the earlier period of exercise. With the $8 \mathrm{~mm}$. bore the exercise could be continued until a steady state was attained. At this later stage of

TABLE 4

Summary of table 3. Respiratory interchange during and after exercise, results given as average minute volume

1. Subject standing at rest.

2. During first continuous 100 steps.

3. During first two minutes rest after 100 steps.

4. During second two minutes rest after 100 steps.

5. Minute volume during fourth minute or later of continuous exercise.

\begin{tabular}{|c|c|c|c|c|c|}
\hline & 1 & 2 & 3 & 4 & 5 \\
\hline \multicolumn{6}{|c|}{ Minute volume uncorrected for temperature or pressure } \\
\hline 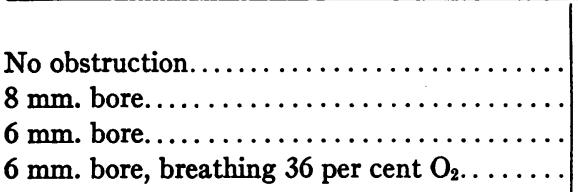 & $\begin{array}{l}\text { liters } \\
9.21 \\
9.66 \\
9.58\end{array}$ & $\begin{array}{l}\text { liters } \\
33.62 \\
27.46 \\
23.05 \\
16.86\end{array}$ & $\begin{array}{l}\text { liters } \\
22.45 \\
22.92 \\
22.88\end{array}$ & $\begin{array}{l}\text { liters } \\
11.95 \\
10.53 \\
11.91\end{array}$ & $\begin{array}{l}\text { liters } \\
53.41 \\
41.90 \\
28.33\end{array}$ \\
\hline \multicolumn{6}{|c|}{$\mathrm{CO}_{2}$ elimination } \\
\hline · & $\begin{array}{l}c c . \text { per } \\
\text { minute }\end{array}$ & $\begin{array}{l}c c \text { per } \\
\text { minute }\end{array}$ & $\begin{array}{l}c c \text {.per } \\
\text { minute }\end{array}$ & $\begin{array}{l}c c \text { per } \\
\text { minute }\end{array}$ & $\begin{array}{l}c c \text { per } \\
\text { minute }\end{array}$ \\
\hline 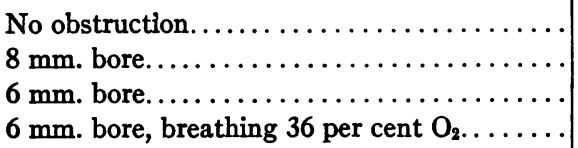 & $\begin{array}{l}258 \\
274 \\
278\end{array}$ & $\begin{array}{r}1,047 \\
970 \\
777 \\
685\end{array}$ & $\begin{array}{l}732 \\
750 \\
836\end{array}$ & $\begin{array}{l}307 \\
269 \\
331\end{array}$ & $\begin{array}{l}1,759 \\
1,763 \\
1,506\end{array}$ \\
\hline \multicolumn{6}{|c|}{$\mathrm{O}_{2}$ absorption } \\
\hline & $\begin{array}{l}\text { cc.per } \\
\text { minute }\end{array}$ & $\begin{array}{l}c c \text {. per } \\
\text { miuute }\end{array}$ & $\begin{array}{l}c c \text { per } \\
\text { minute }\end{array}$ & $\begin{array}{l}c c \text { per } \\
\text { minute }\end{array}$ & $\begin{array}{c}\text { cc.per } \\
\text { minute }\end{array}$ \\
\hline 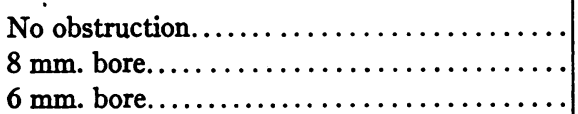 & $\begin{array}{l}320 \\
335 \\
339\end{array}$ & $\begin{array}{l}1,377 \\
1,340 \\
1,198\end{array}$ & $\begin{array}{l}786 \\
808 \\
969\end{array}$ & $\begin{array}{l}331 \\
301 \\
333\end{array}$ & $\begin{array}{l}1,987 \\
2,010\end{array}$ \\
\hline
\end{tabular}

exercise the carbon dioxid eliminated was equal to that eliminated without obstruction. The restricted volume of ventilation was compensated by a higher percentage of carbon dioxid in the expired air. From this we may infer that the tension of this gas was increased both in the alveoli and in the blood, an inference supported by the retention of carbon dioxide that had occurred during the early stage of exercise. 
The amount of oxygen absorbed was not appreciably influenced by the $8 \mathrm{~mm}$. bore either during the first minute and a quarter of exercise or during the later steady period. To compensate for the lessened volume of ventilation a higher percentage of oxygen was removed from the respired air; but there was no reason to assume that this obstruction caused any oxygen want in the body. The subjective discomfort which ied to increased respiratory effort, was caused solely by the increased tension of carbon dioxide. ${ }^{2}$

During the first minute and a quarter of exercise with the $6 \mathrm{~mm}$. bor', the amount of oxygen absorbed was definitely less than when no obstruction was used, the difference averaging $179 \mathrm{cc}$. per minute in the two experiments performed (table 4). The rapidly growing distress which terminated the exercise at about the end of the second minute of exercise must therefore be attributed in part to oxygen want and in part to an accumulation of carbon dioxide in the body. When a mixture containing about 36 per cent oxygen was breathed the respiratory distress during exercise with the $6 \mathrm{~mm}$. bore was distinctly less and the stair climbing could be continued for about four minutes instead of two. The volume of pulmonary ventilation during the first 100 steps was less than when air was breathed (table 4), presumably because with less distress less effort was made to ventilate the lungs. During this period less carbon dioxid was eliminated. Even in the fourth minute of exercise when the percentage of carbon dioxid in the expired air had risen markedly, the total elimination was distinctly short of that put out during continuous exercise with unobstructed breathing. Under these conditions, i.e., breathing an oxygen-rich mixture through the $6 \mathrm{~mm}$. bore, an accumulation of carbon dioxid in the body was the probable cause of the final termination of exercise.

\section{EFFECT OF STENOSIS UPON RECOVERY FROM EXERCISE}

Recovery records were obtained for the four or five minutes following taking 100 steps. These showed in every instance that the main portion of recovery was very rapid (fig. 2). The final stage of recov-

${ }^{2}$ In unpublished experiments by Barnett, Lewis and Hewlett no increase of lactic acid in the urine was found, even after two minutes exercise with the more marked obstruction. 


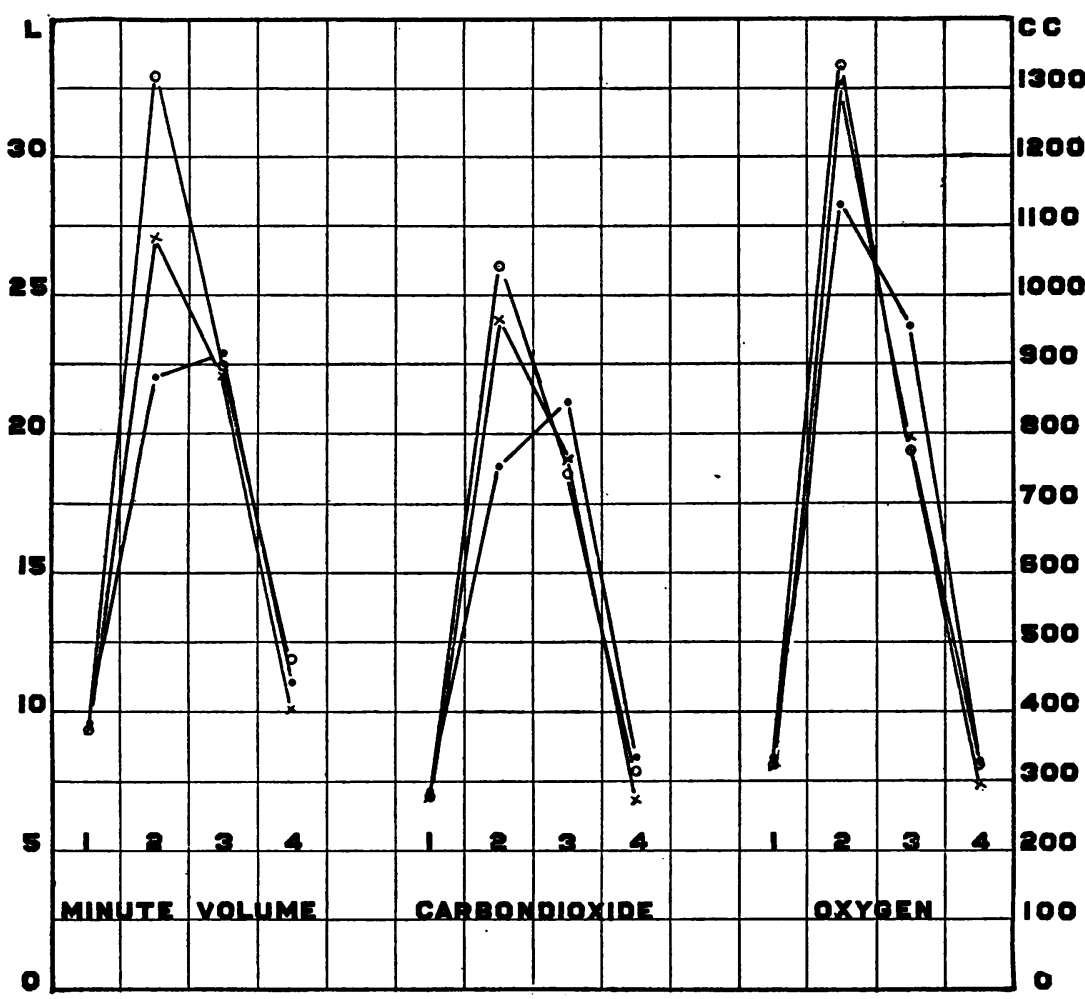

Fig. 2. Effect of Stenosis upon Respiratory Exchange during and After ClImbing 100 Steps

Constructed from table 4. Minute volumes of respiration, carbon dioxide output and oxygen absorption during, (1) rest standing, (2) exercise (100 steps), (3) first two minutes after exercise, and (4) second two minutes after exercise.

$\mathrm{O}=$ no obstruction.

$\mathrm{x}=8 \mathrm{~mm}$. obstruction.

$\bullet=6 \mathrm{~mm}$. obstruction.

TABLE 5

Summary of minute volumes of respiration during successive minutes of rest after climbing 100 steps at a rate of 80 steps per minute

\begin{tabular}{|c|c|c|c|c|c|c|c|}
\hline & \multirow{2}{*}{$\left|\begin{array}{c}\text { Number of } \\
\text { observations } \\
\text { averaged }\end{array}\right|$} & \multirow{2}{*}{$\begin{array}{l}\text { Resting } \\
\text { minute } \\
\text { volume }\end{array}$} & \multicolumn{5}{|c|}{ Minutes after exercise } \\
\hline & & & First & Second & Third & Fourth & Fifth \\
\hline No obstruction. & 10 & 8.5 & 21.9 & 14.1 & 10.4 & 9.5 & 9.0 \\
\hline $8 \mathrm{~mm}$. bore..... & 8 & 8.7 & 26.3 & 15.3 & 10.5 & 9.6 & 9.6 \\
\hline $6 \mathrm{~mm}$. bore.... & 7 & 7.7 & 24.9 & 15.6 & 10.6 & 8.8 & 8.8 \\
\hline
\end{tabular}


ery could not be accurately studied in our experiments because the resting periods which might have served as a basis for comparison had not been obtained after a sufficient preliminary rest period. After this short and moderate exercise, recovery was almost completed during two minutes of rest. At the end of this time the oxygen consumption had returned to the previous resting level, the carbon dioxid output had approached or equalled this level and only the ventilation remained somewhat greater than before the exercise began. During the first two minutes of recovery the excess carbon dioxid retained and in the case of the $6 \mathrm{~mm}$. bore the excess oxygen want developed as a result of obstruction had already been practically equalized. The respiratory volumes during the first two minutes of recovery were slightly greater as a result of the obstructions but the differences were not large, that for the $8 \mathrm{~mm}$. bore being if anything slightly greater than that for the $6 \mathrm{~mm}$. bore. These recovery curves of ventilation gave no indication of the distress experienced during exercise. This point is of interest mainly because in certain other forms of exercise dyspnea the volume of ventilation during recovery is materially greater than when the exercise is accomplished without respiratory effort. Hunt and Dufton (4) have indeed proposed a numerical measure of dyspnea based on the increase of pulmonary ventilation during recovery from measured exercise. It is evident however that such a measure could not be applied to the dyspnea provoked by obstruction.

\section{SUMMARY AND CONCLUSIONS}

1. Artificial obstruction to respiration was produced by breathing through bored corks, the bores being $8 \mathrm{~mm}$. and $6 \mathrm{~mm}$. in diameter.

2. Under resting conditions the $8 \mathrm{~mm}$. bore produced but little subjective and no demonstrable objective effects. The $6 \mathrm{~mm}$. bore caused slight subjective discomfort, and invariably slowed the respiratory rate. In one series of experiments it lessened the average minute volume of respired air.

3. During exercise both bores reduced the respiratory rate and lessened the minute volume of respired air. With the smaller bore a maximum minute volume of approximately 30 liters was attained; but the rapidly increasing distress indicated that this amount of ven- 
tilation was insufficient for the establishment of a steady state. With the larger bore a steady state could be established with a minute volume of approximately 44 liters, in contrast with the minute volume of approximately 53 liters when breathing was not obstructed.

4. When breathing was obstructed, more carbon dioxid was retained during the early stage of the exercise. With the $8 \mathrm{~mm}$. bore, when a steady state was later established, the minute output of carbon dioxid was the same as with unobstructed breathing owing to the higher concentration of this gas in the expired air.

5 . With the $8 \mathrm{~mm}$. bore oxygen absorption was almost unaffectedWith the $6 \mathrm{~mm}$. bore oxygen absorption during the first minute and a quarter was definitely lessened and lack of oxygen contributed to the early discontinuance of the exercise. If a mixture rich in oxygen were breathed, the early distress was less marked and exercise could be continued longer. Eventually however it was discontinued; presumably because, despite a high concentration of carbon dioxid in the expired air, the necessary amount of this gas was not eliminated.

\section{BIBLIOGRAPHY}

1. Morawitz, P., and Siebeck, R. Deutsch. Arch. f. Klin. Med., 1919, xcvii, 201. Die Dyspnoe durch Stenose der Luftwege.

2. Haldane, J. S. Respiration. New Haven, Yale University Press, 1922, 49.

3. Slonaker, J. R. Science, 1923, lvii, 180. A Simple Recording Spirometer.

4. Hunt, G. H., and Dufton, D. Quart. Jour. Med., 1919, xiii, 165. A Numerical Measurement of Dyspnea. 
TABLE 3

Effect of stenosis on respiratory exchange during and after exercise

Period 1. Minute volume, subject standing at rest.

Period 2. During first $1 \frac{1}{4}$ minutes of exercise (100 steps).

Period 3. During first two minutes of rest after climbing 100 steps.

Period 4. During second two minutes of rest after climbing 100 steps.

Period 5. Minute volume during fourth minute or later of continuous exercise.

Volume of ventilation uncorrected for temperature or pressure

No obstruction

\begin{tabular}{|c|c|c|c|c|c|}
\hline Date & 1 & 2 & 3 & 4 & 5 \\
\hline $\begin{array}{l}4 / 1 / 24 \\
4 / 9 / 24 \\
4 / 14 / 24 \\
4 / 15 / 24\end{array}$ & \begin{tabular}{|c|} 
liters per minute \\
9.42 \\
9.27 \\
8.99 \\
9.18
\end{tabular} & $\begin{array}{c}\text { liters } \\
42.05 \\
42.00\end{array}$ & $\begin{array}{l}\text { liters } \\
44.31 \\
45.48\end{array}$ & $\begin{array}{c}\text { liters } \\
24.39 \\
23.42\end{array}$ & $\begin{array}{l}55.02 \\
51.89\end{array}$ \\
\hline \multicolumn{6}{|c|}{$8 \mathrm{~mm}$. obstruction } \\
\hline $\begin{array}{l}4 / 3 / 24 \\
4 / 18 / 24 \\
4 / 21 / 24 \\
4 / 22 / 24\end{array}$ & $\begin{array}{r}9.80 \\
10.08 \\
9.78 \\
8.97\end{array}$ & $\begin{array}{l}33.7 \\
34.96\end{array}$ & $\begin{array}{l}45.3 \\
46.4\end{array}$ & $\begin{array}{l}21.7 \\
20.42\end{array}$ & $\begin{array}{l}41.95 \\
41.86\end{array}$ \\
\hline \multicolumn{6}{|c|}{$6 \mathrm{~mm}$. obstruction } \\
\hline $\begin{array}{l}4 / 4 / 24 \\
4 / 23 / 24\end{array}$ & $\begin{array}{l}9.77 \\
9.39\end{array}$ & $\begin{array}{l}27.5 \\
30.12\end{array}$ & $\begin{array}{l}45.6 \\
45.92\end{array}$ & $\begin{array}{l}23.6 \\
24.05\end{array}$ & \\
\hline
\end{tabular}

Carbon dioxide elimination

No obstruction

\begin{tabular}{|c|c|c|c|c|c|c|c|c|c|c|}
\hline \multirow[t]{2}{*}{ Date } & \multicolumn{2}{|c|}{1} & \multicolumn{2}{|c|}{2} & \multicolumn{2}{|c|}{3} & \multicolumn{2}{|c|}{4} & \multicolumn{2}{|c|}{5} \\
\hline & $\begin{array}{l}c c \text {. per } \\
\text { minute }\end{array}$ & per cent & $c c$ & per cent & $c c$ & per cent & $c c$. & per cent & $c c$. & per cent \\
\hline $4 / 1 / 24$ & 265 & 3.13 & 1,300 & 3.44 & 1,486 & 3.73 & 651 & 2.97 & & \\
\hline $4 / 9 / 24$ & 273 & 3.23 & 1,318 & 3.44 & 1,440 & 3.48 & 577 & 2.70 & & \\
\hline $4 / 14 / 24$ & 238 & 2.87 & & & & & & & 1,840 & 3.63 \\
\hline $4 / 15 / 24$ & 255 & 3.02 & & & & & & & 1,678 & 3.51 \\
\hline
\end{tabular}

$8 \mathrm{~mm}$. obstruction

\begin{tabular}{l|l|l|l|l|l|l|l|l|l|l}
\hline $4 / 3 / 24$ & 287 & 3.23 & 1,202 & 3.93 & 1,488 & 3.62 & 561 & 2.85 & & \\
$4 / 18 / 24$ & 277 & 2.99 & & & & & & & 1,785 & 4.63 \\
$4 / 21 / 24$ & 273 & 3.08 & & & & & & & 1,741 & 4.59 \\
$4 / 22 / 24$ & 258 & 3.16 & 1,222 & 3.84 & 1,512 & 3.58 & 515 & 2.77 & & \\
\hline \multicolumn{10}{c}{6 mm. obstruction } \\
\hline $4 / 4 / 24$ & 286 & 3.19 & 887 & 3.52 & 1,722 & 4.12 & 694 & 3.21 & & \\
$4 / 23 / 24$ & 270 & 3.17 & 1,055 & 3.86 & 1,620 & 3.89 & 631 & 2.89 & & \\
\hline
\end{tabular}


TABLE 3-Continued

Oxygen absorption

No obstruction

\begin{tabular}{|c|c|c|c|c|c|c|c|c|c|c|}
\hline \multirow[t]{2}{*}{ Date } & \multicolumn{2}{|c|}{1} & \multicolumn{2}{|c|}{2} & \multicolumn{2}{|c|}{3} & \multicolumn{2}{|c|}{4} & \multicolumn{2}{|c|}{5} \\
\hline & $\begin{array}{c}c c . \text { per } \\
\text { minute }\end{array}$ & per cent & cc. & per cent & $c c$ & per cent & $c c$. & per cent & $c c$. & per cent \\
\hline $4 / 1 / 24$ & 322 & 3.80 & 1,732 & 4.58 & 1,617 & 4.06 & 627 & 2.86 & & \\
\hline $4 / 9 / 24$ & 338 & 4.00 & 1,712 & 4.47 & 1,526 & 3.68 & 698 & 3.27 & & \\
\hline $4 / 14 / 24$ & 305 & 3.86 & & & & & & & 2,048 & 4.04 \\
\hline $4 / 15 / 24$ & 315 & 3.72 & & & & & & & $|1,927|$ & 4.03 \\
\hline \multicolumn{11}{|c|}{$8 \mathrm{~mm}$. obstruction } \\
\hline $4 / 3 / 24$ & 360 & 4.05 & 1,709 & 5.59 & 1,599 & 3.89 & 640 & 3.25 & & \\
\hline $4 / 18 / 24$ & 330 & 3.56 & & & & & & & 2,020 & 5.24 \\
\hline $4 / 21 / 24$ & 331 & 3.73 & & & & & & & 1,999 & 5.27 \\
\hline $4 / 22 / 24$ & 319 & 3.91 & 1,642 & 5.16 & 1,631 & 3.86 & 565 & 3.04 & & \\
\hline \multicolumn{11}{|c|}{$6 \mathrm{~mm}$. obstruction } \\
\hline $4 / 4 / 24$ & 348 & 3.89 & 1,401 & 5.36 & 2,081 & 4.98 & 714 & 3.30 & & \\
\hline $4 / 23 / 24$ & 330 & 3.88 & 1,596 & 5.84 & 1,795 & 4.31 & 617 & 2.83 & & \\
\hline
\end{tabular}

